\title{
New fixation approach for transverse metacarpal neck fracture: a biomechanical study
}

Yung-Cheng Chiu ${ }^{1,2}$, Ming-Tzu Tsai ${ }^{3}$, Cheng-En Hsu ${ }^{4,5}$, Horng-Chaung Hsu ${ }^{1,2}$, Heng-Li Huang ${ }^{6,7}$ and Jui-Ting Hsu ${ }^{6,7^{*}}$

\begin{abstract}
Background: Fifth metacarpal neck fracture, also known as boxer's fracture, is the most common metacarpal fracture. Percutaneous Kirschner-wire (K-wire) pinning has been shown to produce favorable clinical results. However, the fixation power of K-wires is a major concern. Plate fixation is also a surgical option, but it has the disadvantages of tendon adhesion, requirement of secondary surgery for removal of the implant, and postoperative joint stiffness. A fixation method that causes little soft tissue damage and provides high biomechanical stability is required for patients with fifth metacarpal neck fracture for whom surgical intervention is indicated. The present study proposed fixation using K-wires and a cerclage wire to treat fifth metacarpal neck fracture. The fixation power of this new method was compared with that of K-wires alone and plates.
\end{abstract}

Methods: We used a saw blade to create transverse metacarpal neck fractures in 16 artificial metacarpal bone specimens, which were then treated with four types of fixation as follows: (1) locking plate with five locking bicortical screws (LP group), (2) regular plate with five bicortical screws (RP group), (3) two K-wires (K group), and (4) two K-wires and a figure-of-eight cerclage wire (KW group). The specimens were tested by using cantilever bending testing on a material testing system. The stiffness of the four fixation types was determined by observing force-displacement curves. Finally, the Kruskal-Wallis test was adopted to process the data, and the Mann-Whitney exact test was performed to conduct paired comparison between the fixation types.

Results: The fixation strength levels of the four fixation approaches for treating fifth metacarpal neck fracture were ranked in a descending order of $L P$ group $(24.6 \pm 5.1 \mathrm{~N} / \mathrm{mm}$, median \pm interquartile range) $>$ RP group (22.2 \pm 5 . $8 \mathrm{~N} / \mathrm{mm}) \cong \mathrm{KW}$ group $(20.1 \pm 3.2 \mathrm{~N} / \mathrm{mm})>\mathrm{K}$ group $(16.9 \pm 3.0 \mathrm{~N} / \mathrm{mm})$.

Conclusion: The fixation strength of two K-wires was significantly higher when reinforcement was provided using a figure-of-eight cerclage wire. The strength of the proposed approach is similar to that of a regular plate with five bicortical screws but weaker than that of a locking plate with the same amount of bicortical screws. Cerclage wireintegrated K-wires can be an alternative method that avoids the excessive soft tissue dissection required for plating in open reduction internal fixation for fifth metacarpal neck fracture.

Keywords: Fifth metacarpal neck fracture, Bone plate, K-wire, Cerclage wire

\footnotetext{
* Correspondence: jthsu@mail.cmu.edu.tw; richard@ms32.url.com.tw

${ }^{6}$ School of Dentistry, College of Dentistry, China Medical University, 91

Hsueh-Shih Road, Taichung 40402, Taiwan

${ }^{7}$ Department of Bioinformatics and Medical Engineering, Asia University,

Taichung 413, Taiwan

Full list of author information is available at the end of the article
}

(c) The Author(s). 2018 Open Access This article is distributed under the terms of the Creative Commons Attribution 4.0 International License (http://creativecommons.org/licenses/by/4.0/), which permits unrestricted use, distribution, and reproduction in any medium, provided you give appropriate credit to the original author(s) and the source, provide a link to the Creative Commons license, and indicate if changes were made. The Creative Commons Public Domain Dedication waiver (http://creativecommons.org/publicdomain/zero/1.0/) applies to the data made available in this article, unless otherwise stated. 


\section{Background}

Metacarpal fractures are common orthopedic injuries [1] that account for $13 \%$ of hand fractures and $23 \%$ of forearm fractures [2-4]. The fifth metacarpal neck fracture, also known as boxer's fracture, is the most common type of metacarpal fracture, constituting $50 \%$ of metacarpal fractures [2]. Because of the activity performed by the intrinsic muscles of the hand, patients with fractures in the fifth metacarpal neck are likely to develop volar angulation deformity. If the fracture is treated nonoperatively, volar malunion with dorsal angulation and joint stiffness is common $[5,6]$. Therefore, an increasing number of doctors and patients are opting for surgical treatment instead. The surgical indication of fifth metacarpal fracture is generally considered to be fracture angulation of more than $45^{\circ}$ resulting in a considerable decrease in grip strength and range of motion $[1,7]$.

Of the various fixation methods for metacarpal neck fracture, K-wire fixation is less invasive and has been shown to have outcomes superior to those of plating [1, 3]. Intramedullary pinning has been reported to have better outcomes than crossed and transverse pinning because of its minimal violation of soft tissue [8-10]. Despite causing soft tissue invasion, open reduction and internal fixation (ORIF) still has a role in treating patients with multiple concurrent metacarpal fractures, those who need higher fracture biomechanical stability, those who are unable to protect exposed pins, and those who cannot tolerate a period of immobilization [11]. Plates, available in regular and locking forms, are internal fixation devices commonly used for metacarpal neck fractures. They provide high mechanical strength, but many complications have been reported, including metacarpal head avascular necrosis, nonunion, severe tendon irritation, and high rate of stiffness due to excessive soft tissue damage [1, 7, 12-14]. For the minimization of soft tissue damage and reduction of implant profiles in ORIF, we propose a novel fixation method that integrates K-wires with a cerclage wire. This new method may provide higher mechanical stability and avoid the complications that arise from the use of plates.

The purpose of our study was to investigate the degree of strength that a cerclage wire can add to K-wires and to compare the biomechanical stability of this new fixation method with that achieved using two commonly used plate methods.

\section{Methods}

\section{Specimen preparation}

Obtaining an adequate number of real human specimens with identical bone quality and size is difficult, so we used artificial metacarpal bone (3B Scientific $\mathrm{GmbH}$, Hamburg, Germany) in our experiments. A total of 16 artificial metacarpal bone specimens were employed. A metacarpal neck fracture was generated in the specimens using a 0.4-mm saw blade. The fracture distance was $13 \mathrm{~mm}$ from the distal articular surface.

\section{Fixation approaches and stability test}

The specimens were assigned to four fixation technique groups, and all fixations were performed by a single senior hand surgeon (Yung-Cheng Chiu).

- Group 1-Locking plate with five locking bicortical screws (LP group). The specimens were fixed using a six-hole Y-shaped locking plate and 2.3-mm-diameter locking screws (Stryker, Germany). The locking plate was fixed at the dorsum of the metacarpal using three bicortical proximal locking screws and two bicortical distal locking screws (Fig. 1a).

- Group 2-Regular plate, nonlocking, with five bicortical screws (RP group). The specimens were fixed using a six-hole Y-shaped nonlocking plate and 2.3-mm-diameter compression screws (Stryker, Germany). The nonlocking plate was fixed at the dorsum of the metacarpal with three bicortical proximal compression screws and two bicortical distal compression screws (Fig. 1b).

- Group 3-Two K-wires (K group). The specimens were stabilized using two 1.5 -mm-diameter K-wires inserted from the dorsal medial and lateral sides of the metacarpal head, penetrated the fracture site, and fed out from the proximal volar cortex; fracture reduction was maintained with manual axial compression during the surgery (Fig. 1c).

- Group 4-Two K-wires with figure-of-eight cerclage wire (KW group). The specimens were stabilized using two 1.5-mm-diameter K-wires inserted from the dorsal medial and lateral sides of the metacarpal head, penetrated through the fracture site, and fed out from the proximal volar cortex; fracture reduction was maintained with manual axial compression during the surgery. Subsequently, an 18-gauge needle was mounted on an electric drill to serve as the wire guide. Two wire guides were drilled transversely into the distal and proximal parts of the fractured metacarpal parallel at approximately $0.5 \mathrm{~cm}$ from the fracture site. A 25-gauge stainless steel wire was used to pass the two wire guides to shape the wire into a figure of eight at the dorsum of the metacarpal after the two needles were withdrawn (Fig. 1d and Fig. 2).

Before mechanical testing, the proximal end of each specimen was held in a custom fixture using molded epoxy clamps. Cantilever bending tests were conducted using a material testing system (JSV-H1000, Japan Instrumentation System, Nara, Japan) (Fig. 3). Following preloading to $5 \mathrm{~N}$, a perpendicular load was applied to 

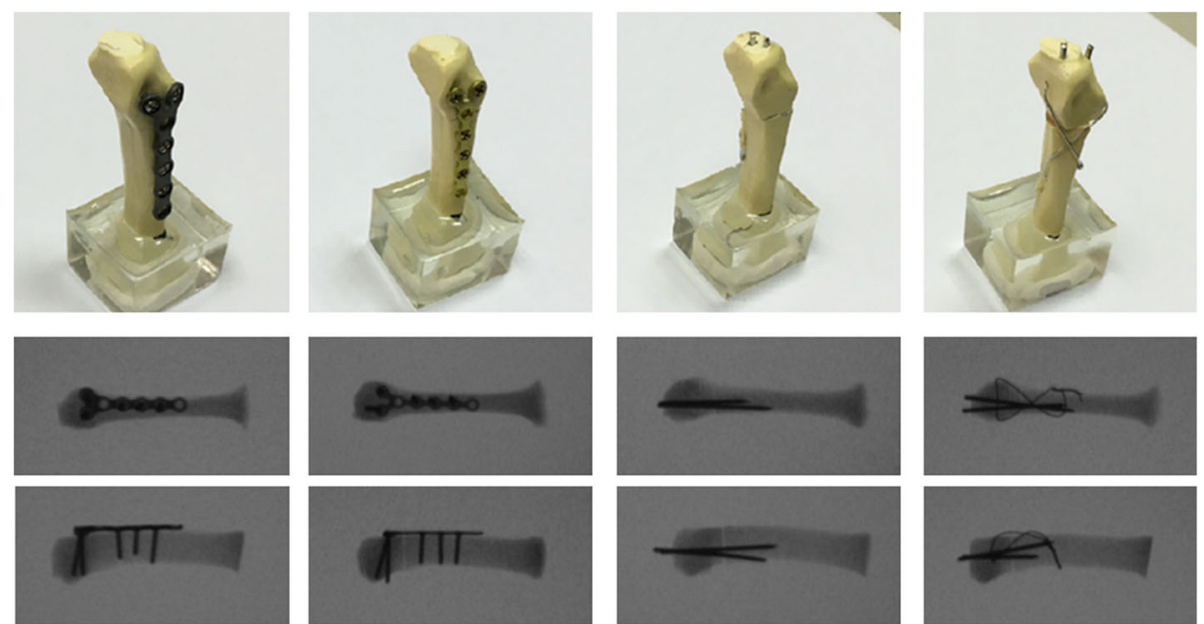

Fig. 1 Artificial metacarpal bones and four fixation types of the metacarpal neck fracture. a Locking plate with five locking bicortical screws (LP group). b Regular plate with five bicortical screws (RP group). c Two K-wires (K group). d Two K-wires and a figure-of-eight cerclage wire (KW group). Radiographs of the four fixation types in superior and lateral views are also shown

the dorsal side of the specimen at a distance of $53 \mathrm{~mm}$ from the fixture until failure. The crosshead speed was $10 \mathrm{~mm} / \mathrm{min}$. The experimental setup was similar to that used in other studies [12, 15]. Force-displacement data were recorded, and the bending stiffness of each specimen was determined.

\section{Statistical analysis}

The stiffness of the specimens with metacarpal neck fracture and four fixation types are summarized as the median value (interquartile range [IQR]). The KruskalWallis test was used to compare the differences between the four fixation types. Post hoc pairwise comparisons were conducted using the Mann-Whitney test. Statistical significance was set at $P<0.05$. All statistical analyses were performed using SPSS Version 19 (IBM Corporation, Armonk, NY, USA).

\section{Results}

The experimental results are presented in Table 1 and Fig. 4. The highest median stiffness was obtained for the LP group specimens and was equal to $24.6 \pm 5.1 \mathrm{~N} / \mathrm{mm}$. The median of the RP group $(22.2 \pm 5.8 \mathrm{~N} / \mathrm{mm})$ was slightly higher than that of the KW group $(20.1 \pm 3.2 \mathrm{~N} /$ $\mathrm{mm})$, but the difference was nonsignificant. The most unstable fixation type was that in the $\mathrm{K}$ group, for which the median stiffness was only $16.9 \pm 3.0 \mathrm{~N} / \mathrm{mm}, 15.9$ and $23.9 \%$ lower than that for the KW and RP groups, respectively. The fixation stiffness of the four types of fixation in fifth metacarpal neck fracture thus followed the order LP group $>\mathrm{RP}$ group $\cong \mathrm{KW}$ group $>\mathrm{K}$ group.

\section{Discussion}

Fifth metacarpal neck fracture is a common hand fracture. K-wires and plates are the commonly used internal
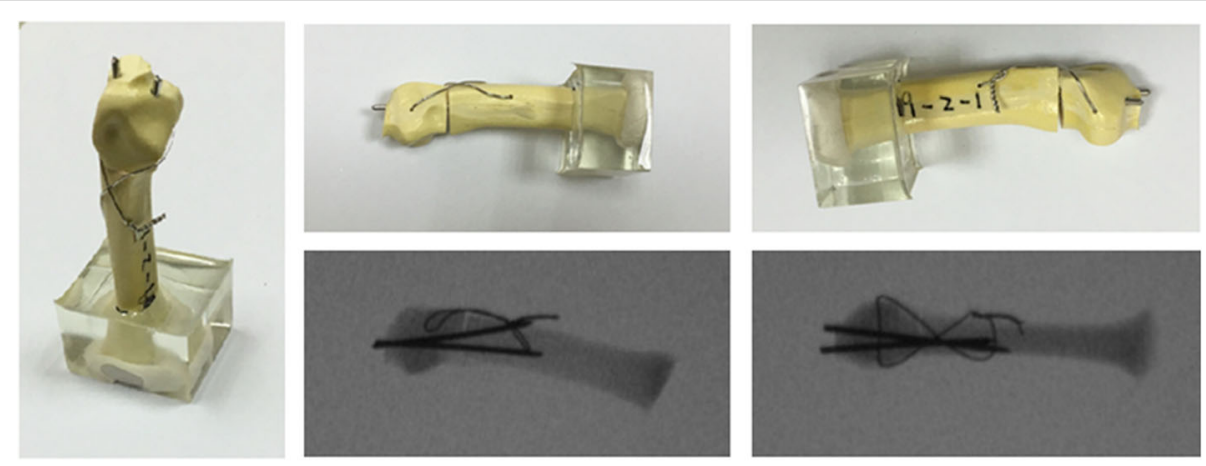

Fig. 2 Details of the fixation approach employing two K-wires and a figure-of-eight cerclage wire (KW group) 


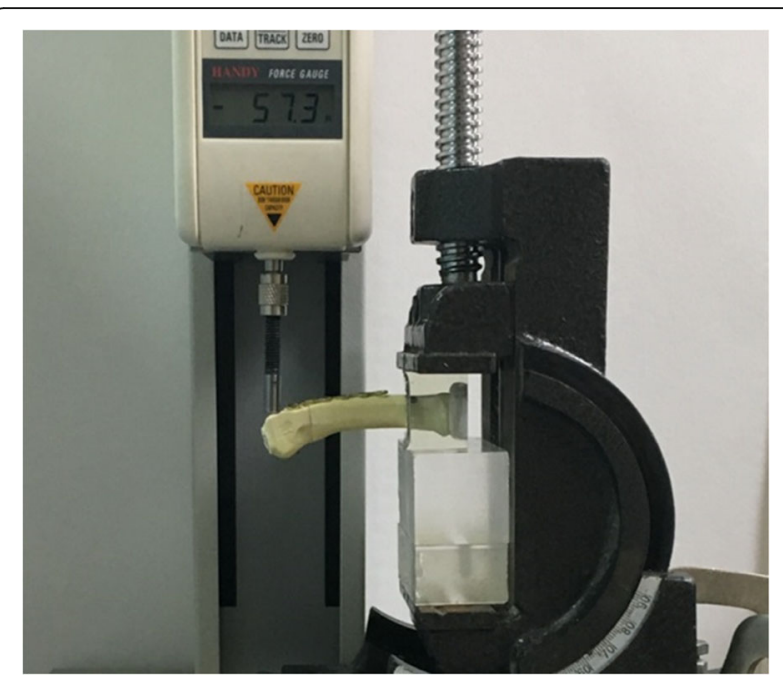

Fig. 3 Experimental setup for cantilever bending tests. The specimen has fixation of a locking plate with five locking bicortical screws

fixation devices; however, numerous complications and high rates of postoperative joint stiffness are reported due to the excessive soft tissue damage that these devices cause $[1,7,12-14]$. Herein, we proposed a mixed fixation of $\mathrm{K}$-wires and a cerclage wire. This fixation approach requires less soft tissue dissection than plate insertion, has mechanical strength comparable to that of a nonlocking plate, and may avoid the complications caused by plate fixation. Additionally, the cost of the proposed approach is considerably lower than that of plate fixation.

In this study, we used artificial metacarpal bones to conduct experiments because of difficulty with acquiring bones from corpses with consistent qualities. Fifth metacarpal neck fracture is often experienced by young people, but obtaining metacarpal bones from the corpses of young people is particularly difficult. Consequently, studies have tended to conduct experiments using porcine or artificial metacarpal bones [12, 16-18]. This study compared the strength of different osteosynthesis techniques for fixation and therefore entailed selecting specimens with almost identical geometrics and material properties. Accordingly, artificial bones were employed because of their uniformity and consistency [19].

Table 1 Stiffness (unit: N/mm) of the four fixation types used to fix metacarpal neck fracture

\begin{tabular}{llllll}
\hline Group & Median & IQR & Max & Min & $P$ \\
\hline LP & 24.6 & 5.1 & 27.9 & 21.3 & 0.001 \\
RP & 22.2 & 5.8 & 27.1 & 20.4 & \\
K & 16.9 & 3.0 & 19.5 & 15.9 & \\
KW & 20.1 & 3.2 & 21.8 & 18.5 & \\
\hline
\end{tabular}

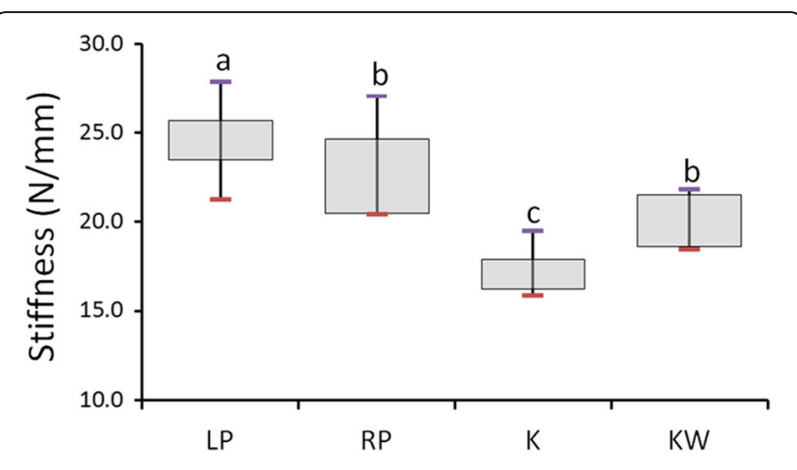

Fig. 4 Box plot showing the stiffness of the four fixation types. Post hoc pairwise comparisons were conducted using the Mann-Whitney test; use of the same letter indicates no significant difference at the 0.05 level

According to the American Society for Testing and Materials (ASTM) F-1839-08, "Standard Specification for Rigid Polyurethane Foam for Use as a Standard Material for Testing Orthopaedic Devices and Instruments" states that "the uniformity and consistent properties of rigid polyurethane foam make it an ideal material for comparative testing of bone screws and other medical devices and instruments" [20].

We conducted cantilever bending tests, which differ slightly from the physiological loading tests commonly used in a clinical setting. However, no existent in vitro biomechanical test is able to reflect actual amounts of physiological loading. In addition to the cantilever bending test, previous studies have adopted tests including the three-point bending test [17], modified three-point bending test $[13,21,22]$, four-point bending test $[16$, $18]$, and torsional test $[12,23]$. We employed the cantilever bending test instead of a bending test mainly because the aim of the study was to explore fixation approaches for metacarpal neck fracture not metacarpal shaft fracture. Previously, the maximum fracture force and stiffness were common indexes for scholars to determine fixation strength [12, 14, 16, 17, 21, 23]. In this study, however, the strength was assessed by evaluating the stiffness alone. We assumed that during fracture healing, no matter what fixation is used, refracture of the fifth metacarpal neck as a result of an extremely strong active or passive force does not and should never occur. By contrast, stiffness indicates the structure stiffness of a fixation. Thus, measuring stiffness is more meaningful than measuring the maximum fracture force in clinical practice.

Research has identified that bone plate fixation is the strongest fixation [16, 24-27]. Similarly, the present study determined that the stiffness of the fixation using two K-wires was lower than that using a locking plate and regular plate. Malasitt et al. [13] compared the strength of K-wire and locking plate fixation by 
conducting experiments on porcine second metacarpals and revealed that the K-wire fixation exhibited higher initial stiffness. The experiments of the present study verified that the stiffness of locking plate fixation (24.61 $+5.12 \mathrm{~N} / \mathrm{mm}$ ) was higher than that of regular plate fixation $(22.17+5.12 \mathrm{~N} / \mathrm{mm})$. Likewise, Ochman et al. [14] implemented modified three-point bending tests to examine pig metacarpal specimens with various types of fixation. The results indicated that when monocortical bone fixation was employed, the stiffness of the fixation using a locking plate $(83+35 \mathrm{~N} / \mathrm{mm})$ was higher than that using a regular plate $(46+12 \mathrm{~N} / \mathrm{mm})$. Doht et al. [21] also conducted modified three-point bending tests on pig metacarpal bones. Despite the mean stiffness of the locking plate group exceeding that of the regular plate group, the difference was nonsignificant.

The stiffness of the KW group was lower than that of the LP group, but no significant difference was discovered between that of the KW and RP groups. Additionally, KW fixation exhibited much greater stiffness than K-wire fixation, indicating that using two K-wires and one figure-of-eight cerclage wire to treat fifth metacarpal neck fracture is reliable.

An increasing amount of evidence is demonstrating that some innovative procedures and modern, fashionable, expensive locking plates do not always achieve superior outcomes to nonsurgical treatment or use of a simple fixation device (e.g., K-wires) [28-30]. Orthopedic and trauma surgeons should consider the possibility of nonsurgical treatment before resorting to an operation. Maffulli indicated that if surgical intervention is inevitable, fixation using devices with a low profile should be prioritized [31]. Pinning fractured bones using K-wires is a reliable approach in treating boxer's fracture. Compared with plate fixation, K-wire fixation requires less soft tissue dissection [9] and thus results in a lower rate of postoperative extensor tendon adhesion. Nonetheless, K-wire fixation does have some disadvantages, including exposed hardware, a longer period of immobilization, and lower resistance to angulation and rotational deformity force wire migration, and these disadvantages make this method inappropriate for some patients [32, 33]. Requiring much less soft tissue dissection than what is needed in plate fixation, K-wire and figure-of-eight cerclage wire fixation prevents $\mathrm{K}$-wires from migrating, avoids hardware exposure, and has similar strength to plate fixation, resisting deformity forces and thus potentially reducing the postoperative immobilization period. The proposed surgical treatment modality (two K-wires and one figure-of-eight cerclage wire) had lower profile than plates, which may reduce complications caused by using a plate, including tendon irritation, joint stiffness, and metacarpal head ischemia necrosis. Regarding the cost-effectiveness, the costs of locking plate and regular plate fixation at our institution are US\$1500 and US\$200, respectively, whereas that of KW fixation using two K-wires and one figure-of-eight cerclage wire is only US\$5. Therefore, given our aforementioned results and the present discussion, we conclude that KW fixation is a feasible alternative fixation for treating fifth metacarpal neck fracture.

The approach of integrating a figure-of-eight cerclage wire to two K-wires and adopted in the present study was inspired by the use of tension band wiring (TBW) fixation [34] in a previous study to treat patella transverse fracture. TBW is widely employed to treat limb fractures, including distal clavicle fracture [35], olecranon fracture [36], and medial malleolar fracture [37]. The advantages of TBW are (1) higher antirotation force [3] compared with that in K-wire fixation, (2) higher antibending force compared with that in wire fixation, and (3) lower profile compared with the bone plate, which reduces tendon irritation. Therefore, bones heal more effectively when TBW is applied at the tension side of a fracture [38, 39]. In our proposed method, TBW is inserted in the dorsal side of the fractured fifth metacarpal neck because this fixation is mechanically advantageous. Usually, the fractured fifth metacarpal neck is tilted toward the palm because of the traction power of intrinsic muscle, meaning that the dorsal side is the tension side. By using the fixation of two K-wires and one figure-of-eight cerclage wire, the dorsal tension side became the compression side, enabling the dorsal volar cortex (fractured bones) to heal faster.

This study was subject to several limitations. First, to ensure that the specimens used had the same geometry and material properties, we used artificial bones to conduct experiments. Although artificial bones have been used previously $[12,40]$, they are not able to simulate the actual properties of human bones such as inhomogeneity and anisotropy and do not have the actual structure of trabecular bones. Second, as was the case in most previous in vitro biomechanical experiments, the fracture pattern created was a simple fracture [12, 16-18]. Third, we conducted cantilever bending tests to assess the fixation strength of the distinct fixation types, and such testing does not reflect all actual physiological conditions; in fact, no mechanical testing is able to reflect all actual physiological conditions. Fourth, as previous studies have indicated [18, 19], artificial and animal bones do not contain soft tissues such as muscles, ligaments, and tendons. Although the absolute values measured in this study will hence be different from those under actual conditions, we held that this difference would not influence the ranking of the four fixation types regarding their fixation strength. In the future, we will collect clinical results to evaluate the effect of soft tissue when the two K-wires and a 
figure-of-eight cerclage wire fixation approach is employed.

\section{Conclusion}

In this study, we proposed a new fixation approach with two K-wires and one figure-of-eight cerclage wire for treating fifth metacarpal neck fracture in patients for whom open reduction internal fixation is indicated. On the basis of the experimental design and limitations, we conclude that the figure-of-eight cerclage wire significantly increases the biomechanical stability of the two $\mathrm{K}$-wires. The fixation strength of the proposed fixation is similar to that of a regular plate with five bicortical screws but weaker than that of a locking plate with five bicortical screws. Integrating a figure-of-eight cerclage wire with $\mathrm{K}$-wires is an alternative fixation method that avoids the excessive soft tissue dissection that occurs in open reduction internal fixation for fifth metacarpal neck fracture.

\section{Abbreviations}

K group: Two K-wire group; KW group: Two K-wires and a figure-of-eight cerclage wire group; LP group: Locking plate with five locking bicortical screw group; RP group: Regular plate with five bicortical screw group; TBW: Tension band wiring

\section{Funding}

This work was supported by grants from the Ministry of Health and Welfare Taiwan (MOHW107-TDU-B-212-123004). In addition, this study was partially supported by the Ministry of Science and Technology, Taiwan (MOST 1062221-E-039-002)

\section{Availability of data and materials}

The datasets used and analyzed during the current study are available from the corresponding author on reasonable request.

\section{Authors' contributions}

$\mathrm{YC}, \mathrm{HCH}$, and $\mathrm{JH}$ participated in the design of the study. $\mathrm{YC}, \mathrm{CH}, \mathrm{HLH}$, and $\mathrm{JH}$ carried out the measurement. YC, MT, CH, and JH carried out the statistical analysis. YC, MT, and $\mathrm{JH}$ conceived of the study, participated in its design and coordination, and drafted the manuscript. All authors read and approved the final manuscript.

\section{Ethics approval and consent to participate}

Not applicable.

\section{Consent for publication}

Not applicable.

\section{Competing interests}

No authors of this study have any financial and personal relationships with other people or organizations, which could result in an inappropriate influence of this study. The authors declare that they have no competing interests.

\section{Publisher's Note}

Springer Nature remains neutral with regard to jurisdictional claims in published maps and institutional affiliations.

\section{Author details}

${ }^{1}$ School of Medicine, China Medical University, Taichung 404, Taiwan. 2Department of Orthopedic Surgery, China Medical University Hospital, Taichung 404, Taiwan, Republic of China. ${ }^{3}$ Department of Biomedical Engineering, Hungkuang University, Taichung 433, Taiwan. ${ }^{4}$ Department of Orthopaedics, Taichung Veterans General Hospital, Taichung 407, Taiwan.
${ }^{5}$ Sports Recreation and Health Management Continuing Studies-Bachelor's Degree Completion Program, Tunghai University, Taichung 407, Taiwan. ${ }^{6}$ School of Dentistry, College of Dentistry, China Medical University, 91 Hsueh-Shih Road, Taichung 40402, Taiwan. 'Department of Bioinformatics and Medical Engineering, Asia University, Taichung 413, Taiwan.

Received: 17 April 2018 Accepted: 12 July 2018

Published online: 25 July 2018

\section{References}

1. Padegimas EM, Warrender WJ, Jones CM, llyas AM. Metacarpal neck fractures: a review of surgical indications and techniques. Arch Trauma Res. 2016;5(3):e32933.

2. Boussakri $H$, Elidrissi M, Azarkane M, Bensaad S, Bachiri M, Shimi M, Elibrahimi A, Elmrini A. Fractures of the neck of the fifth metacarpal bone, treated by percutaneous intramedullary nailing: surgical technique, radiological and clinical results study (28 cases). Pan Afr Med J. 2014;18:187.

3. Facca S, Ramdhian R, Pelissier A, Diaconu M, Liverneaux P. Fifth metacarpal neck fracture fixation: locking plate versus K-wire? Orthop Traumatol Surg Res. 2010;96(5):506-12

4. Potenza V, Caterini R, De Maio F, Bisicchia S, Farsetti P. Fractures of the neck of the fifth metacarpal bone. Medium-term results in 28 cases treated by percutaneous transverse pinning. Injury. 2012;43(2):242-5.

5. Harris AR, Beckenbaugh RD, Nettrour JF, Rizzo M. Metacarpal neck fractures: results of treatment with traction reduction and cast immobilization. Hand (N Y). 2009:4(2):161-4

6. Wong KP, Hay RA, Tay SC. Surgical outcomes of fifth metacarpal neck fractures - a comparative analysis of dorsal plating versus tension band wiring. Hand Surg. 2015;20(1):99-105.

7. Kollitz KM, Hammert WC, Vedder NB, Huang Jl. Metacarpal fractures: treatment and complications. Hand (N Y). 2014;9(1):16-23.

8. Wong TC, Ip FK, Yeung SH. Comparison between percutaneous transverse fixation and intramedullary K-wires in treating closed fractures of the metacarpal neck of the little finger. J Hand Surg. 2006;31(1):61-5.

9. Schädel-Höpfner M, Wild M, Windolf J, Linhart W. Antegrade intramedullary splinting or percutaneous retrograde crossed pinning for displaced neck fractures of the fifth metacarpal? Arch Orthop Trauma Surg. 2007;127(6):435-40.

10. Winter M, Balaguer T, Bessiere C, Carles M, Lebreton E. Surgical treatment of the boxer's fracture: transverse pinning versus intramedullary pinning. J Hand Surg Eur Vol. 2007;32(6):709-13.

11. Leinberry C, Ukomadu U, Ilyas A, Metacarpal fractures and carpometacarpal fracture-dislocations. 1st ed New Delhi: Jaypee Brothers Medical Publishers Ltd;: 2013;

12. Barr C, Behn AW, Yao J. Plating of metacarpal fractures with locked or nonlocked screws, a biomechanical study: how many cortices are really necessary? Hand (N Y). 2013;8(4):454-9.

13. Malasitt P, Owen JR, Tremblay M-A, Wayne JS, Isaacs JE. Fixation for metacarpal neck fracture: a biomechanical study. Hand. 2015;10(3):438-43.

14. Ochman S, Vordemvenne T, Paletta J, Raschke MJ, Meffert RH, Doht S. Experimental fracture model versus osteotomy model in metacarpal bone plate fixation. TheScientificWorldJOURNAL. 2011;11:1692-8.

15. Nicklin S, Ingram S, Gianoutsos MP, Walsh WR. In vitro comparison of lagged and nonlagged screw fixation of metacarpal fractures in cadavers. J Hand Surg. 2008:33(10):1732-6.

16. Bozic KJ, Perez LE, Wilson DR, Fitzgibbons PG, Jupiter JB. Mechanical testing of bioresorbable implants for use in metacarpal fracture fixation. J Hand Surg. 2001;26(4):755-61.

17. Curtis BD, Fajolu $\mathrm{O}$, Ruff ME, Litsky AS. Fixation of metacarpal shaft fractures: biomechanical comparison of intramedullary nail crossed K-wires and platescrew constructs. Orthop Surg. 2015;7(3):256-60.

18. Liodaki E, Wendlandt R, Waizner K, Schopp BE, Mailander P, Stang F. A biomechanical analysis of plate fixation using unicortical and bicortical screws in transverse metacarpal fracture models subjected to 4-point bending and dynamical bending test. Medicine. 2017;96(27):e6926.

19. Elfar J, Stanbury S, Menorca RMG, Reed JD. Composite bone models in orthopaedic surgery research and education. J Am Acad Orthop Surg. 2014;22(2):111.

20. American Society for Testing and Materials A. ASTM F1839 - 08 Standard specification for rigid polyurethane foam for use as a standard material for testing orthopedic devices and instruments. 
21. Doht S, Meffert RH, Raschke MJ, Blunk T, Ochman S. Biomechanical analysis of the efficacy of locking plates during cyclic loading in metacarpal fractures. TheScientificWorldJOURNAL. 2014;2014:648787.

22. Ochman S, Doht S, Paletta J, Langer M, Raschke MJ, Meffert RH. Comparison between locking and non-locking plates for fixation of metacarpal fractures in an animal model. J Hand Surg. 2010;35(4):597-603.

23. Eu-Jin Cheah A, Behn AW, Comer G, Yao J. A biomechanical analysis of 2 constructs for metacarpal spiral fracture fixation in a cadaver model: 2 large screws versus 3 small screws. J Hand Surg. 2017;42(12):1033 e1-6.

24. Black D, Mann R, Constine R, Daniels A. Comparison of internal fixation techniques in metacarpal fractures. J Hand Surg. 1985;10(4):466-72.

25. Firoozbakhsh KK, Moneim MS, Doherty W, Naraghi FF. Internal fixation of oblique metacarpal fractures. A biomechanical evaluation by impact loading. Clinical Orthopaedics and Related Research. 1996;325:296-301.

26. Mann R, Black D, Constine R, Daniels A. A quantitative comparison of metacarpal fracture stability with five different methods of internal fixation. J Hand Surg. 1985;10(6):1024-8.

27. Meunier MJ, Hentzen E, Ryan M, Shin AY, Lieber RL. Predicted effects of metacarpal shortening on interosseous muscle function. J Hand Surg. 2004;29(4):689-93.

28. Handoll H, Brealey S, Rangan A, Torgerson D, Dennis L, Armstrong A, Chuang L-H, Cross B, Dumville J, Gardner S. Protocol for the ProFHER (PROximal Fracture of the Humerus: Evaluation by Randomisation) trial: a pragmatic multi-centre randomised controlled trial of surgical versus nonsurgical treatment for proximal fracture of the humerus in adults. BMC Musculoskelet Disord. 2009;10(1):140.

29. Handoll H, Keding A, Corbacho B, Brealey S, Hewitt C, Rangan A. Five-year follow-up results of the PROFHER trial comparing operative and nonoperative treatment of adults with a displaced fracture of the proximal humerus. The Bone \& Joint Journal. 2017;99(3):383-92.

30. Rangan A, Handoll H, Brealey S, Jefferson L, Keding A, Martin BC, Goodchild L, Chuang L-H, Hewitt C, Torgerson D. Surgical vs nonsurgical treatment of adults with displaced fractures of the proximal humerus: the PROFHER randomized clinical trial. JAMA. 2015;313(10):1037-47.

31. Maffulli N. We are operating too much. J Orthop Traumatol. 2017;18(4):289-92.

32. Sharma H, Taylor GR, Clarke NM. A review of K-wire related complications in the emergency management of paediatric upper extremity trauma. Ann R Coll Surg Engl. 2007;89(3):252-8.

33. Wong KY, Mole R, Gillespie P. Kirschner wire breakage during removal requiring retrieval. Case reports in surgery. 2016;2016:7515760.

34. Osteotomies MM, Müller ME, Allgöwer M, Schneider R, et al., editors. Manual of internal fixation: techniques recommended by the AO-ASIF Group. Berlin Heidelberg New York: Springer-Verlag; 1979.

35. Kao F-C, Chao E-K, Chen C-H, Yu S-W, Chen C-Y, Yen C-Y. Treatment of distal clavicle fracture using Kirschner wires and tension-band wires. J Trauma Acute Care Surg. 2001;51(3):522-5.

36. Claessen F, van den Bekerom MPJ, van Dijk CN, Carel Goslings J, Kerkhoffs G, Doornberg JN. Tension band wiring for simple olecranon fractures: evaluation of surgical technique. J Orthop Traumatol : official journal of the Italian Society of Orthopaedics and Traumatology. 2017:18(3):275-81.

37. Ostrum RF, Litsky AS. Tension band fixation of medial malleolus fractures. J Orthop Trauma. 1992;6(4):464-8.

38. Ali M, Kuiper J, John J. Biomechanical analysis of tension band wiring (TBW) of transverse fractures of patella. Chin J Traumatol. 2016;19(5):255-8.

39. Zens M, Goldschmidtboeing F, Wagner F, Reising K, Sudkamp NP, Woias P. Polydimethylsiloxane pressure sensors for force analysis in tension band wiring of the olecranon. Technol Health Care : official journal of the European Society for Engineering and Medicine. 2016;24(6):909-17.

40. Hiatt SV, Begonia MT, Thiagarajan G, Hutchison RL. Biomechanical comparison of 2 methods of intramedullary K-wire fixation of transverse metacarpal shaft fractures. J Hand Surg. 2015:40(8):1586-90.

Ready to submit your research? Choose BMC and benefit from:

- fast, convenient online submission

- thorough peer review by experienced researchers in your field

- rapid publication on acceptance

- support for research data, including large and complex data types

- gold Open Access which fosters wider collaboration and increased citations

- maximum visibility for your research: over $100 \mathrm{M}$ website views per year

At BMC, research is always in progress.

Learn more biomedcentral.com/submissions 